Metin et al.

\title{
A META-ANALYTIC STUDY OF EVENT RATE EFFECTS ON GO/NO-GO PERFORMANCE IN ATTENTION-DEFICIT/HYPERACTIVITY DISORDER
}

\section{Authors:}

Baris Metin ${ }^{1}$, Herbert Roeyers ${ }^{1}$, Roeljan Wiersema ${ }^{1}$, Jaap van der Meere ${ }^{2}$, Edmund SonugaBarke $^{1,3}$

${ }^{1}$ Department of Experimental-Clinical and Health Psychology, Ghent University, Belgium

${ }^{2}$ Department of Clinical and Developmental Neuropsychology, University of Groningen, The Netherlands

${ }^{3}$ Developmental Brain-Behaviour Unit, School of Psychology, University of Southampton. U.K.

Address Correspondence to: Baris Metin

Faculty of Psychology and Educational Sciences

Experimental Clinical and Health Psychology

Henri Dunantlaan 2, B-9000

Gent Belgium

Tel: +32-9-2648620

E-mail: baris.metin@ugent.be

\section{Word count}

Abstract: 249

Body: 3994

Five figures and one supplemantary information included. 


\begin{abstract}
Background: According to the State Regulation Deficit (SRD) model event rate (ER) is an important determinant of performance of children with Attention-Deficit/Hyperactivity Disorder (ADHD). Fast ER is predicted to create over-activation and produce errors of commission while slow ER is thought to create under-activation marked by slow and variable reaction times (RT) and errors of omission.
\end{abstract}

Method: To test these predictions, we conducted a systematic search of the literature to identify all reports of comparisons of ADHD and control individuals' performance on Go/NoGo tasks published between 2000 and 2011. In one analysis we included all trials with at least two event rates and calculated the difference between ER conditions. In a second analysis, we used meta-regression to test for the moderating role of ER on ADHD vs. control differences seen across Go/No-Go studies.

Results: There was a significant and disproportionate slowing of reaction time in ADHD relative to controls on trials with slow event rates in both meta-analyses. For commission errors, the effect sizes were larger on trials with fast event rates. No ER effects were seen for RT variability. There were also general effects of ADHD on performance for all variables which persisted after effects of ER were taken in account.

Conclusions: The results provide support for the SRD model of ADHD by showing the differential effects of fast and slow ER. The lack of an effect of ER on RT variability suggests that this behavioral characteristic may not be a marker of cognitive energetic effects in ADHD.

Keywords: ADHD, state regulation, meta-analysis, Go/No-Go, event rate, task performance. 


\section{Introduction}

Attention-Deficit/Hyperactivity Disorder (ADHD) is a life-span disorder which causes significant academic, social and behavioral problems. In principle identifying the neuropsychological deficits in ADHD could stimulate therapeutic innovation by helping to identify new targets for novel treatments (1). Identifying which deficits are implicated in ADHD is complicated by a number of factors. First, children with ADHD, as a group, perform poorly on a wide range of laboratory tasks even when they are designed to tap very different neuropsychological processes (2). Indeed, it is increasingly clear that there is substantial pathophysiologic heterogeneity in the ADHD population in terms of the specific patterns of deficits implicated - some individuals display one type of neuropsychological profile while others show a different one $(2,3)$. For instance, while once thought of as the core deficit in ADHD, executive function deficits are reported in only a subset of individuals (4).

Second, there is accumulating evidence for the context-dependent nature of deficits when they do occur - performance of an individual subject may vary from setting to setting as a function of the motivational and energetic state that they engender (5). For instance, performance on a wide range of cognitive tasks is affected in non-specific ways by the rate at which stimuli are presented (i.e., event rate (ER)), which is determined by inter-stimulus interval (ISI) $(6,7)$. These ER effects have been observed on tasks of different sorts including go/no-go (8), stop signal (9) vigilance (10) and associative learning (11) tasks. Such task nonspecific ER effects have been explained in different ways (5). The most often invoked explanation is based on the cognitive energetic model of Sanders (12). This extends the basic information processing framework by integrating concepts such as effort, arousal and activation so that task performance is influenced not only by cognitive capacities but also by 
Metin et al.

environmentally-determined levels of activation and arousal and the extent to which variations in these can be managed to ensure optimal performance. The model predicts an inverted-U shaped curve relating cognitive energetic factors to performance with both over and under activation (linked to fast and slow ERs) having potentially adverse effects if not effectively managed (7). The state regulation deficit (SRD) model of ADHD, builds on this perspective. It postulates that children with ADHD have problems with effectively allocating their effort to properly regulate activation states (13). Because cognitive energetic processes are general rather than task specific, the SRD predicts that ADHD children's performance across a range of different tasks tapping a diversity of executive and non-executive processes will be adversely affected by either speeding up or slowing down the ER. More specifically the model predicts a pattern of ADHD-related under-activation and slow inattentive responding under slow ER, and fast impulsive responding, produced by over-activation under fast ER conditions.

An alternative explanation of ER effects on performance is provided by Delay Aversion model $(5,14)$. According to this model individuals with ADHD act on their environment to escape or avoid delay. In fixed delay situations this is said to be achieved by reallocating attention to more interesting stimuli that make time pass more quickly. Thus the DAv model predicts a pattern of task disengagement on longer trials with slower ER and longer inter-stimulus intervals (i.e., greater delay). As such it differs from the SRD model by predicting that performance of ADHD individuals will deteriorate in a linear fashion with longer intervals resulting in lower performance (i.e., adverse effects on slow but not fast ER trials). 
Metin et al.

To test predictions of the SRD model of ADHD we conducted a systematic review and meta-analyses of the effects of ER on performance on Go/No-Go (GNG) tasks. Our strategy was to focus on one task in order to optimize homogeneity. The GNG task was chosen as it has been used frequently with ADHD populations. In the GNG task participants are presented consecutively with a series of Go stimuli to which they have to make a simple choice response and then occasionally with an alternative No-Go stimulus to which they have to withhold their response. The task is well suited for testing the SRD model as it allows the estimation of variables in a range of performance domains: mean reaction time (MRT), errors of commission (EOC), errors of omission (EOO) and response time variability (measured by standard deviation of reaction time-SDRT). While the SRD model predicts general energetic, rather than cognitive process-specific effects, it makes some specific predictions with regard to different GNG performance parameters: Compared to controls, ADHD children are predicted to experience over-activation in the fast ERs and under-activated in the slow ERs (6, 7). This over-activation will produce more impulsive EOC during fast ERs. On the other hand, under-activation during slow ERs will produce slower and more variable MRT and a greater number of errors of omission (EOO) typical of inattentive performance. Two types of meta-analyses were performed to test these predictions. First, we estimated the differential impact of ER on ADHD vs. control performance as a function of different ERs presented within the same studies. We then attempted to replicate these within-study effects by using meta-regression techniques to test the extent to which ER levels in different studies explained the between study heterogeneity of ADHD vs. control performance differences. 


\section{Method}

\section{Search strategy}

We searched Medline databases for studies published between January 2000 and December 2011. For this purpose, we used combinations of the term ADHD with the following keywords (using AND): reaction time, accuracy, continuous performance test, Go/No-Go, inhibition, event rate and inter-stimulus interval. Records were then screened for initial eligibility on the basis of titles and abstracts. Potential records were then screened on the basis of full-text articles. At this stage we removed studies where GNG paradigms had less than $50 \%$ Go trials. There was no age restriction and studies conducted with adolescent or adult participants were also included. Studies which used a highly variable range of ISI (variability $>1 \mathrm{sec}$ ) and did not report the results for each ISI were excluded. Self-paced and cued tasks were also excluded. In order to maximize homogeneity, tasks with additional stimuli (e.g., cue or feedback) were excluded from analysis as these would provide extra stimulation for subjects and the "real" ISI is therefore difficult to determine.

\section{Coding, calculation and synthesis of the effect sizes}

We undertook two analyses. Both analyses employed comprehensive Meta-Analysis software (version 2.2.057, Biostat Inc., NJ, USA). In both analyses the outcome variables were the MRT, EOC and SDRT. Too few studies $(\mathrm{N}=5)$ reported inattentive errors of omission in the slow ER and so this outcome, which would provide a more direct assessment of inattentive errors, was not included in the analysis. When summary statistics were not reported, effect size (ES) was extracted from test statistics (e.g., t values, means and p values) using the appropriate formula. The other extracted variables were mean age of each group, ISI used, the percentage of males in the ADHD and the control group, percentage of Go and No- 
Metin et al.

Go trials in the task, number of trials, co-morbidity and the medication status. ER (i.e., interstimulus interval) was defined as the time interval between the onsets of two consecutive stimuli.

The first analysis was restricted to those studies where ER was manipulated as a within-subject variable (i.e., had trials with two or more ER levels). We used these data to estimate the differential effect of ER on ADHD vs. control performance for the variables MRT, EOC and SDRT. The method proposed by Borenstein et al. (15) was employed to compare different outcomes or time-points within a study. First, the standard mean difference (SMD) between the groups at each ES is calculated using the recommended formula - mean of the ADHD group minus the mean of the control group divided by the pooled standard deviation. Second, the ES for differential effect of ER on ADHD vs. control performance is calculated by subtracting the SMD of the group difference at $\mathrm{SMD}^{\text {fast }}$ from that at $\mathrm{SMD}^{\text {slow }}$ and then variance of this synthetic ES was calculated using the formula $V=V 1+V 2-2 r \sqrt{ } \boldsymbol{I} \sqrt{V 2}$, where V is the variance of the synthetic ES, V1 and V2 are the variance for the effect sizes for the two outcomes and $\mathrm{r}$ is the correlation between the outcomes. This is equivalent to calculating the ES for the group $\mathrm{x}$ event rate interaction and so we will refer to it as $\mathrm{ES}^{\text {group } \mathrm{x}}$ event rate . The $\mathrm{ES}^{\text {fast }}, \mathrm{ES}^{\text {slow }}$ and $\mathrm{ES}^{\text {group x event rate }}$ calculated for each study were then combined using a random effects model to give overall ES estimates. One difficulty with this method is that it requires that the within-subject correlations between performance under the different conditions are known and these are often not reported. To deal with this issue we ran a sensitivity analysis based on the correlation in other studies to estimate a range of effect sizes and $\mathrm{p}$ values. 
Metin et al.

The second analysis adopted a different approach in order to utilize all GNG studies meeting our entry criteria even where only one ER was employed. First, we calculated the SMD for ADHD vs. control effects for each outcome in each individual study using the same formula as in the first analysis. The SMDs were then combined across studies using the random effects method. The $\mathrm{Q}$ and $\mathrm{I}^{2}$ statistics were calculated as an estimate of betweenstudy heterogeneity in SMD. We then performed a meta-regression to examine the independent effect of ER (as well as a number of other factors such as the difference between the percentage of the males within groups and age of the ADHD group) in predicting between study variation in ADHD vs. control SMDs on our three dependent variables. For the regression analysis, a random effects regression model was used (15) assuming a heterogeneous distribution of effect sizes for the studies sharing the same predicted value. One difficulty with such a regression analysis is that more studies have used a fast or a moderate ER than a slow one. Thus there are fewer studies in the slow ER range which reduces our power to accurately estimate the effects of ER on performance. In order to address this point we maximized the number of studies with a slow ER by choosing data for the slowest ER condition when studies had more than one ER condition. We also conducted sensitivity analyses to explore whether the observed effects were dependent on the small numbers of studies with unusual age and gender composition. The first was related to age and involved excluding all studies with a mean age above $11(\mathrm{~N}=8)$. The rationale for choosing the age of 11 was to exclude studies conducted with adolescent populations and to explore whether the regression results were driven by effects in these samples of older participants. The second related to gender composition of samples; we excluded studies $(\mathrm{N}=7)$ with high difference for male percentage (>20) between clinical and control groups. In other sensitivity analyses we excluded studies $(\mathrm{N}=2)$ with a small number of trials $(<50)$ and with 
Metin et al.

fewer than $60 \%$ Go trials $(\mathrm{N}=3)$ to explore whether the regression results depended on confounding effects of studies with fewer number trials or lower percentage of Go trials.

\section{Results}

Figure 1 gives the PRISMA flow chart for the identification of studies according to our inclusion criteria. The number of studies excluded for each exclusion criterion are also summarized in the figure. A total of 30 studies met the entry criteria (16-45). Of those, 19 studies had just one ER level and 11 studies manipulated ER as a within-subject variable. In each case ER was manipulated by block - with different ERs presented in separate test blocks (see supplementary material for study details and summary statistics).

\section{Estimating the differential effect of ER using within-subject study data}

Eleven studies provided data for the calculation of both $\mathrm{SMD}^{\text {slow }}$ and $\mathrm{SMD}^{\text {fast }}$ for MRT and EOC. Ten studies reported sufficient data for an analysis of SDRT. Based on the four studies from which we obtained the correlation coefficient (see supplementary material), we imputed correlations ranging from 0.6-0.8, 0.4-0.7 and 0.6-0.8 for MRT, EOC and SDRT analyses respectively for the seven studies with unreported correlation. The mean fast ER was $1.8 \mathrm{sec}(1.25-2.3 \mathrm{sec})$ and the mean slow ER was $6.9 \mathrm{sec}(4.25-8.3 \mathrm{sec})$. For $M R T$, groups differed significantly at both slow and fast ER $\left(\mathrm{SMD}^{\text {slow }}=0.56\right.$; CIs 0.36 to 0.76 ; $\mathrm{SMD}^{\text {fast }}=0.33$; CIs 0.13 to 0.53 ). The forest plots for both analyses are given in Figure 2 . $\mathrm{ES}^{\text {group x event rate }}$ was significant (ES between 0.22 and 0.26 , p value between 0.004 and 0.003 ) with bigger SMDs between ADHD and control participants on slower ERs demonstrating a 
Metin et al.

disproportionate slowing of RT in the ADHD group on those trials. For $E O C$, again the groups differed significantly at both slow and fast ERs $\left(\mathrm{SMD}^{\text {slow }}=0.37\right.$; CIs 0.18 to 0.57; $\mathrm{SMD}^{\text {fast }}=0.57$; CIs 0.37 to 0.76 ) (See Figure 3 for forest plots). ES ${ }^{\text {group } x \text { event rate }}$ was significant (ES btw -0.17 and -0.18, p value btw 0.006 and 0.001 ) with bigger SMDs between ADHD and control participants on fast ER trials. For $S D R T$, the groups differed significantly at both slow and fast $\mathrm{ER}\left(\mathrm{SMD}^{\text {slow }}=0.75\right.$; CIs 0.48 to $1.03 ; \mathrm{SMD}^{\text {fast }}=0.85$; CIs 0.63 to 1.08$)$ (See Figure 4 for forest plots). ES $S^{\text {group x event rate }}$ was not significant (p value btw 0.03 and 0.11 ).

\section{Estimating the differential effect of ER using between study data}

Twenty-five studies contributed to the MRT, 29 to the EOC and 22 to the SDRT analysis. One study contributed two independent data sets to each analysis: one comparing a pediatric ADHD group and the other an adolescent group along with separate age matched control groups (17). There was a significant between group effect overall - slower MRT was seen for $\mathrm{ADHD}$ samples $(\mathrm{SMD}=0.28(95 \%$ CIs 0.14 to 0.43$)$. There was significant betweenstudy heterogeneity $\left(\mathrm{Q}(25)=67.15, \mathrm{p}<0.001, \mathrm{I}^{2}=62.77\right)$. Variation in SMD between studies was significantly predicted by ER $(\mathrm{z}=2.88, \mathrm{p}=0.004)$ and age (ES decreasing with increasing age, $\mathrm{z}=-2.43, \mathrm{p}=0.02)$. However heterogeneity was still significant after including ER and age in the model $(\mathrm{Q}(24)=52.91, \mathrm{p}=0.001 ; \mathrm{Q}(20)=56.93, \mathrm{p}<0.001$ respectively $)$. Figure 5 plots the MRT SMD as a function of ER. There was a significant overall group difference for EOC $(\mathrm{SMD}=0.44,95 \% \mathrm{CIs} 0.34$ to 0.54$)$. There was also significant heterogeneity $(\mathrm{Q}(29)=46.07$, $\left.\mathrm{p}=0.02, \mathrm{I}^{2}=37.05\right)$. ER and age did not account for a significant proportion of the betweengroup SMD variance between studies $(\mathrm{z}=-0.65 \mathrm{p}=0.51, \mathrm{z}=-0.61, \mathrm{p}=0.54$ respectively) (see supplementary material for the scatter plot). For SDRT, the group effect (SMD $=0.66 ; 95 \%$ CIs 0.51 to 0.81 ) was highly significant. The between-study ES heterogeneity was also significant $\left(\mathrm{Q}(22)=54.07, \mathrm{p}<0.001, \mathrm{I}^{2}=59.32\right)$. ER was not a predictor of between-group 
Metin et al.

SMDs $(\mathrm{z}=0.4, \mathrm{p}=0.69)$ (see supplementary material for the scatter plot). However there was an inverse relationship between age and SMDs $(\mathrm{z}=-2.29, \mathrm{p}=0.02)$.

\section{Sensitivity analyses}

For MRT, restricting analyses to studies with participants under the age of 11 years and to studies with a small difference in gender composition had no effect on the results $(\mathrm{z}=2.14, \mathrm{p}=0.03 ; \mathrm{z}=2.5, \mathrm{p}=0.01$ respectively). For EOC the same restrictions did not change the results either (for age restriction $\mathrm{z}=-0.92 \mathrm{p}=0.35$; for gender restriction $\mathrm{z}=-0.4, \mathrm{p}=0.68$ ). The sensitivity analyses for number of trials and $\%$ of Go trials were also not significant for none of the variables.

\section{Discussion}

Consistent with the predictions of the SRD model, GNG performance in ADHD was differentially affected by ER. First, both analyses found an impact of ER on the SMD between ADHD and control participants for MRT in the predicted direction: There was a disproportionate slowing of ADHD responding with reducing ERs. From an SRD perspective this effect is regarded as being due to under-activation in people with ADHD brought about by a failure to adjust their activation level according to the demands of long and boring tasks $(6,7)$. The second prediction - of a disproportionate increase in EOCs under fast ER condition in ADHD relative to controls - was also supported by the within-subject analysis. However, this effect was weaker than for the MRT and the slope, although in the right direction, was not significant in the between-study meta-regression. This might be explained by the greater power in within-subject analysis due to taking into account the correlation between measurements. From the SRD perspective this increase in impulsive errors is due to the failure to moderate an over-activated state induced by the fast ERs $(6,7,46)$. Slower responding in slow ERs and more errors in the fast ERs is also consistent with a possible role 
Metin et al.

altered response strategy in ADHD. A complete speed-accuracy trade-off (SATO) analysis requires access to trial-by-trial data which was not available in our case but future studies could examine contribution of these factors to the state regulation deficits. However, a provisional analysis of SATO based on averaged data for each study found no relationship between error rates and MRT.

Despite these positive findings implicating the effect of ER in ADHD performance, it is also clear that ER is not the sole determinant of ADHD-related deficits on GNG tasks. Both analyses found strong effects of group not accounted for only by ER: ADHD children had longer MRTs and made more EOCs on both high and low ER trials. This conclusion is supported by the meta-regression analysis of between-subject design studies where ER accounted for only a proportion of the between-study heterogeneity. Across all variables, a substantial proportion of the ADHD group differences were not due to ER manipulations. Thus the current results are in line with previous research which found that although motivational and energetic factors, such as reward, can have substantial effect on ADHD performance, they rarely fully alleviate deficits - this could be due either to a common partial response or alternatively normalization in only a sub-group of individuals with ADHD $(20,28)$. If this latter case were true it would provide further evidence of neuropsychological heterogeneity in ADHD.

The negative result for SDRT is also worthy of further discussion given that response variability has been suggested to be a particularly important marker of state regulation problems in ADHD in the past (47). There are at least two possible explanations for the lack of an ADHD-specific effect of ER on this outcome. First, SDRT may not be a sufficiently sensitive measure of the energetic processes. For instance, increased variability in ADHD could be related to a number of different putative cognitive processes (20) such as motor timing (48), top-down executive control (49), impaired suppression of default mode network 
Metin et al.

(50) and attentional lapses (47). Second, it has been suggested that response variability represents a non-specific finding which is seen in multiple types of disorders (28). In this view SDRT, although associated with ADHD, may not be related to ADHD-specific processes but be a more general marker of psychopathology (51). However, this objection may also hold for MRT and EOCs. Thus, exploring the specificity of these outcomes for ER effects and finding more specific measures of state regulation deficits could be the aim of future studies.

Can other models explain the ER effects in the data? The Delay aversion model (DAv) $(5,14)$ also makes predictions with regard to ER effects. In this model ADHD behavior is motivated by the escape or avoidance of delay. When there are options with different delay outcomes, individuals with ADHD will choose the least delayed option all else being equal producing impulsive choice (52). When no choice exists and delay is to some extent imposed (as is the case in the GNG paradigms included in the current meta-analysis), then individuals with ADHD are predicted to engage in patterns of off-task inattentive behaviors that have been shown to reduce the subjective experience of delay. The performance corollary of such behavior are higher errors of omission and long and variable RTs when the length of delay between stimuli increases. From a different point of view, one might argue that slower RT and higher variability in ADHD on slow ER trials are due to attentional lapses (47) linked to increased interference from the so-called default mode brain network (50). The finding of longer RTs on slow ER trials is consistent with both of these models. However, neither DAv nor default mode network model make specific predictions about EOC and certainly would not predict a disproportionate increase of EOC on fast ER trials as found in the current study. Thus, these models do not offer a parsimonious explanations of ER effects seen in this study. At the same time ADHD is not a neuropsychologically homogeneous condition. Therefore it 
Metin et al.

is quite possible that the association between ER and performance is multi-factorially determined with different patterns of deficits linked to SRD, DAv and the default mode interference, leading to problems attending on slow ER trials. The large SMD between ADHD and controls for the MRT effects compared to the EOC effects would be consistent with this.

While interpreting these results one needs to take into account of a number of limitations of the current analysis. First, the aim was to identify the effect of ER on performance and a number of studies have been excluded as they did not report ER explicitly or used a highly variable presentation rate. Therefore the summary effect sizes calculated do not represent all the studies published and should be evaluated carefully. Second, while between study variance can be explained partially by ER and age other factors such as task setup, instructions, severity of ADHD symptoms, diagnostic criteria and scales are likely to be important. The analysis of such factors is not within the scope of this study given the limited information available in specific papers relating to these factors. Although we could not analyze the specific factors that may cause this heterogeneity we took account of it by using a random effects model which assumes that the true effect size varies from study to study.

There is potentially a number of clinical implications of the results. First, they may help us design more appropriate ways of delivering information in the classroom: the slower the information is presented, the more sluggish the ADHD children may become. On the other hand, a fast teaching style and presentation of abundant stimuli may induce an over-activated impulsive response style. Therefore the content of the lecture and the environment could be adapted to tailor the stimulation level to an optimal level. This may require increased use of information and communication technology to promote active and personalized learning. Second, it may be possible to train individuals with ADHD to cope with a broader range of ER settings through methods like neurofeedback and cognitive training that can improve management of their energetic resources. Third, they can highlight the potential of targeting 
Metin et al.

brain systems related to energetic factors - for instance noradrenaline pathways originating in the locus ceruleus (LC) is likely to be the main neurochemical system involved in regulating the arousal state (53). The interplay between the LC and cerebral cortex mediates adaptation to the changing environmental conditions such as changing ER. A methodological implication of our findings relates to choosing the optimal GNG task design for the future studies. Given the apparent context dependent nature of task performance in ADHD - studies of cognitive test performance in ADHD should, as a matter of course, include a range of ERs that cover the full range of the values explored here. We would recommend at least a fast condition (ISI $\leq 2 \mathrm{sec}$ ) to capture errors of commission and a slow condition (ISI $\geq 6 \mathrm{sec}$ ) to induce low and variable inattentive responses.

In summary, the SRD model provides the most parsimonious explanation of the differential ER effects on the GNG performance of ADHD and control participants - more EOC on fast ER trials and longer RTs on slow ER trials. However, the finding that group differences exist over and above those related to ER and the possibility that other deficits could account for these differences highlight the neuropsychological heterogeneity in ADHD. Therefore, future studies should aim to develop theories of ADHD which could better explain this sort of neuropsychological heterogeneity by modeling the presence of different deficits in different individuals in the ADHD population (54). 
Metin et al.

\section{Acknowledgements}

This study is supported by Fund for Scientific Research-Flanders

We thank Norbert Börger, Libbe Kooistra, Ruth Raymaekers, Susan Crawford and Jeffrey

Epstein for providing us with the additional statistics from their study data.

\section{Disclosures}

Herbert Roeyers has served as an advisor to Shire and received research support and conference attendance support from Shire and Lilly

Edmund Sonuga-Barke declares the following competing interests: Recent speaker board:

Shire, UCB Pharma. Current \& recent consultancy: UCB Pharma, Shire. Current \& recent research support: Janssen Cilag, Shire, Qbtech, Flynn Pharma. Advisory Board: Shire, Flynn Pharma, UCB Pharma, Astra Zeneca. Conference support: Shire.

All other authors declare no competing interests to disclose. 


\section{References}

1. Sonuga-Barke EJS, Halperin JM (2010): Developmental phenotypes and causal pathways in attention deficit/hyperactivity disorder: potential targets for early intervention? J Child Psychol Psych 51: 368-389.

2. Willcutt EG, Doyle AE, Nigg, JT, Faraone SV, Pennington BF (2005): Validity of the executive function theory of attention-deficit/hyperactivity disorder: a metaanalytic review. Biol Psychiatry 57: 1336-1346.

3. Nigg JT (2005): Neuropsychologic theory and findings in attentiondeficit/hyperactivity disorder: the state of the field and salient challenges for the coming decade. Biol Psychiatry 57: 1424-1435.

4. Lambek R, Tannock R, Dalsgaard S, Trillingsgaard A, Damm D, Thomsen PH (2010): Validating neuropsychological subtypes of ADHD: how do children with and without an executive function deficit differ? J Child Psychol Psych 51: 895904.

5. Sonuga-Barke EJS, Wiersema JR, van der Meere JJ, Roeyers H (2010): Contextdependent dynamic processes in attention deficit/hyperactivity disorder: differentiating common and unique effects of state regulation deficits and delay aversion. Neuropsychol Rev 20: 86-102.

6. van der Meere, JJ (2002): The role of attention. In: S. Sandberg editor. Hyperactivity Disorders of Childhood, $2^{\text {nd }}$ ed. New York: Cambridge University Press, pp 162-213. 
7. Sergeant J (2004): Modeling attention-deficit/hyperactivity disorder: A critical appraisal of the cognitive-energetic model. Biol Psychiatry 57:1248-1255.

8. van de Meere JJ, Stemerdink N, Gunning B (1995): Effects of presentation rate of stimuli on response inhibition in ADHD children with and without tics. Perceptual Motor Skills, 81, 259-262.

9. Scheres A, Oosterlaan J, Sergeant J (2001): Response execution and inhibition in children with $\mathrm{AD} / \mathrm{HD}$ and other disruptive disorders: the role of behavioural activation. J Child Psychol Psychiatry 42: 347-57.

10. Chee P, Logan G, Schachar R, Lindsay P, Wachsmuth R (1989): Effects of event rate and display time on sustained attention in hyperactive, normal, and control children. Journal of abnormal child psychology 17: 371-91.

11. Conte R, Kinsbourne M, Swanson J, Zirk H, Samuels M (1986): Presentation rate effects on paired associate learning by attention deficit disordered children. Child Development 57: 681-687.

12. Sanders AF (1983): Towards a model of stress and human performance. Acta Psychologia 53: 61-97.

13. van der Meere JJ, Börger NA, Wiersema JR (2010): ADHD: State Regulation and Motivation. CML Psychiatry 21: 14-20.

14. Sonuga-Barke EJS, Taylor E, Sembi S, Smith J (1992): Hyperactivity and delay aversion-I. The effect of delay on choice. J Child Psychol Psych 33: 387-398.

15. Borenstein M, Hedges LV, Higgins JPT, Rothstein HR (2009): Introduction to Meta-analysis, $1^{\text {st }}$ ed. West Sussex, UK: John Wiley \& Sons Ltd.

16. Berlin L, Bohlin G, Nyberg L, Janols LO (2004): How well do measures of inhibition and other executive functions discriminate between children with ADHD and controls? Child Neuropsychol, 10: 1-13. 
17. Bitsakou P, Psychogiou L, Thompson M, Sonuga-Barke EJS (2008): Inhibitory deficits in attention-deficit/hyperactivity disorder are independent of basic processing efficiency and IQ. J Neur Trans 115: 261-268.

18. Börger N, van der Meere JJ (2000): Motor control and state regulation in children with ADHD: a cardiac response study. Biol Psychol 51: 247-267.

19. Desman C, Petermann F, Hampel P (2008): Deficit in response inhibition in children with attention deficit/hyperactivity disorder (ADHD): impact of motivation? Child Neuropsychol 14: 483-503.

20. Epstein JN, Langberg JM, Rosen PJ, Graham A, Narad ME, Antonini TN, et al. (2011): Evidence for higher reaction time variability for children with ADHD on a range of cognitive tasks including reward and event rate manipulations.

Neuropsychology 25: 427-441

21. Groom MJ, Bates AT, Jackson GM, Calton TG, Liddle PF, Hollis C (2008): Event-related potentials in adolescents with schizophrenia and their siblings: a comparison with attention-deficit/hyperactivity disorder. Biol Psychiatry 63: 784792.

22. Hervey AS, Epstein JN, Curry JF, Tonev S, Eugene Arnold L, Keith Conners C, et al. (2006): Reaction time distribution analysis of neuropsychological performance in an ADHD sample. Child Neuropsychol 12: 125-140

23. Johnson K, Kelly SP, Bellgrove MA, Barry E, Cox M, Gill M, et al. (2007): Response variability in attention deficit hyperactivity disorder: evidence for neuropsychological heterogeneity. Neuropsychologia 45: 630-638.

24. Kerns K, McInerney RJ, Wilde NJ (2001): Time reproduction, working memory, and behavioral inhibition in children with ADHD. Child Neuropsychol 7: 21-31. 
Metin et al.

25. Klein C, Wendling K, Huettner P, Ruder H, Peper M (2006): Intra-subject variability in attention-deficit hyperactivity disorder. Biol Psychiatry 60: 10881097.

26. Koschack J, Kunert HJ, Derichs G, Weniger G, Irle E (2003): Impaired and enhanced attentional function in children with attention deficit/hyperactivity disorder. Psychol Medicine 33: 481-489.

27. Kooistra L, Crawford S, Gibbard B, Ramage B, Kaplan BJ (2010): Differentiating attention deficits in children with fetal alcohol spectrum disorder or attentiondeficit-hyperactivity disorder. Dev Med Child Neurol 52: 205-211.

28. Kuntsi J, Wood AC, van der Meere JJ, Asherson P (2009): Why cognitive performance in ADHD may not reveal true potential: findings from a large population-based sample. J Int Neuropsychol Soc 15: 570-579.

29. McNally M, Crocetti D, Mahone EM, Denckla MB, Suskauer SJ, Mostofsky SH (2010): Corpus callosum segment circumference is associated with response control in children with attention-deficit hyperactivity disorder (ADHD). J Child Neurol 25: 453-462.

30. O'Brien JW, Dowell LR, Mostofsky SH, Denckla MB, Mahone EM (2010): Neuropsychological Profile of Executive Function in Girls with Attention-Deficit/ Hyperactivity Disorder. Arch Clin Neuropsychol 25: 656-670.

31. Raymaekers R, Antrop I, van der Meere JJ, Wiersema JR, Roeyers H (2007): HFA and ADHD: a direct comparison on state regulation and response inhibition. $J$ Clin Exp Neuropsychol 29: 418-427.

32. Rovet JF, Hepworth SL (2001): Dissociating attention deficits in children with ADHD and congenital hypothyroidism using multiple CPTs. J Child Psychol Psychiatry. 42: 1049-1056. 
Metin et al.

33. Rubia K, Smith A, Taylor E (2007): Performance of children with attention deficit hyperactivity disorder (ADHD) on a test battery of impulsiveness. Child Neuropsychol 13: 276-304.

34. Ryan M, Martin R, Denckla MB, Mostofsky SH, Mahone EM. (2010): Interstimulus jitter facilitates response control in children with ADHD. $J$ Int Neuropsychol Soc 16: 388-393.

35. Uebel H, Albrecht B, Asherson P, Börger N, Butler L, Chen W, et al. (2010): Performance variability, impulsivity errors and the impact of incentives as genderindependent endophenotypes for ADHD. J Child Psychol Psych 51: 210-218.

36. van der Meere JJ, Börger N, Potgieter ST, Pirila S, De Cock P (2009): Very Low Birth Weight and Attention Deficit/Hyperactivity Disorder. Child Neuropsychol 15: 605-618.

37. Van De Voorde S, Roeyers H, Verté S, Wiersema JR (2010): Working memory, response inhibition, and within-subject variability in children with attentiondeficit/hyperactivity disorder or reading disorder. J Clin Exp Neuropsychol 32: 366-379.

38. Van De Voorde S, Roeyers H, Wiersema JR (2010): Error monitoring in children with ADHD or reading disorder: An event-related potential study. Biol Psychology 84: 176-185.

39. Vaurio RG, Simmonds DJ, Mostofsky SH (2009): Increased intra-individual reaction time variability in attention-deficit/hyperactivity disorder across response inhibition tasks with different cognitive demands. Neuropsychologia 47: 23892396. 
Metin et al.

40. Wada N, Yamashita Y, Matsuishi T, Ohtani Y, Kato H (2000): The test of variables of attention (TOVA) is useful in the diagnosis of Japanese male children with attention deficit hyperactivity disorder. Brain Dev 22: 378-382.

41. Wiersema JR, van der Meere JJ, Roeyers H (2009): ERP correlates of error monitoring in adult ADHD. J Neur Trans 116: 371-379.

42. Wiersema JR, van der Meere JJ, Roeyers H, Van Coster R, Baeyens D (2006): Event rate and event-related potentials in ADHD. J Child Psychol Psych 47: 560567.

43. Wiersema R, van der Meere JJ, Antrop I, Roeyers H (2006): State regulation in adult ADHD: an event-related potential study. J Clin Exp Neuropsychol 28: 11131126.

44. Wodka EL, Mahone EM, Blankner JG, Larson JCG, Fotedar S, Denckla MB, et al. (2007): Evidence that response inhibition is a primary deficit in ADHD. J Clin Exp Neuropsychol 29: 345-356.

45. Yang B-R, Chan RCK, Gracia N, Cao X-Y, Zou X-B, Jing J, et al. (2011): Cool and hot executive functions in medication-naive attention deficit hyperactivity disorder children. Psychol Med 41: 2593-2602.

46. Sergeant J (2000): The cognitive-energetic model: an empirical approach to attention-deficit hyperactivity disorder. Neurosci Biobehav Rew 24: 7-12.

47. Leth-Steensen C, Elbaz ZK, Douglas VI (2000): Mean response times, variability, and skew in the responding of ADHD children: a response time distributional approach. Acta psychologica 104: 167-90.

48. Rubia K (2001): Neuropsychological analyses of impulsiveness in childhood hyperactivity. The British Journal of Psychiatry 179: 138-143. 
Metin et al.

49. Bellgrove M a, Hester R, Garavan H (2004): The functional neuroanatomical correlates of response variability: evidence from a response inhibition task. Neuropsychologia 42: 1910-6.

50. Sonuga-Barke EJS, Castellanos FX (2007): Spontaneous attentional fluctuations in impaired states and pathological conditions: a neurobiological hypothesis. Neurosci Biobehav Rew 31: 977-986.

51. Geurts HM, Grasman RPPP, Verté S, Oosterlaan J, Roeyers H, van Kammen SM, et al. (2008): Intra-individual variability in ADHD, autism spectrum disorders and Tourette's syndrome. Neuropsychologia 46: 3030-3041.

52. Marco R, Miranda A, Schlotz W, Melia A, Mulligan A, Müller U et al. (2009). Delay and reward choice in ADHD: an experimental test of the role of delay aversion. Neuropsychology 23: 367-380.

53. Aston-Jones G, Rajkowski J, Cohen J (1999): Role of locus coeruleus in attention and behavioral flexibility. Biol Psychiatry 46:1309-1320.

54. Fair DA, Bathula D, Nikolas MA., Nigg JT (2012): Distinct neuropsychological subgroups in typically developing youth inform heterogeneity in children with ADHD. Proc Natl Acad Sci 109:6769-74. 
Figure 1. Prisma diagram for the flow of information through different phases of the review.

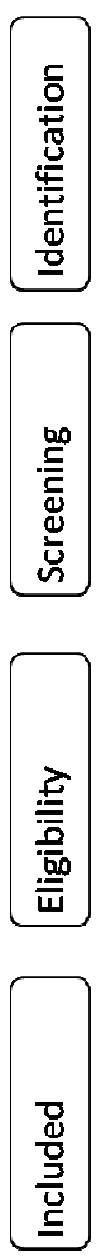

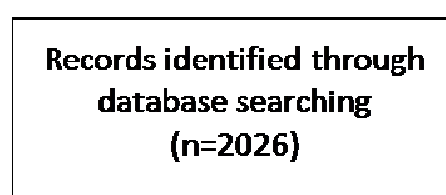

$(\mathrm{n}=\mathbf{2 0 2 6}$

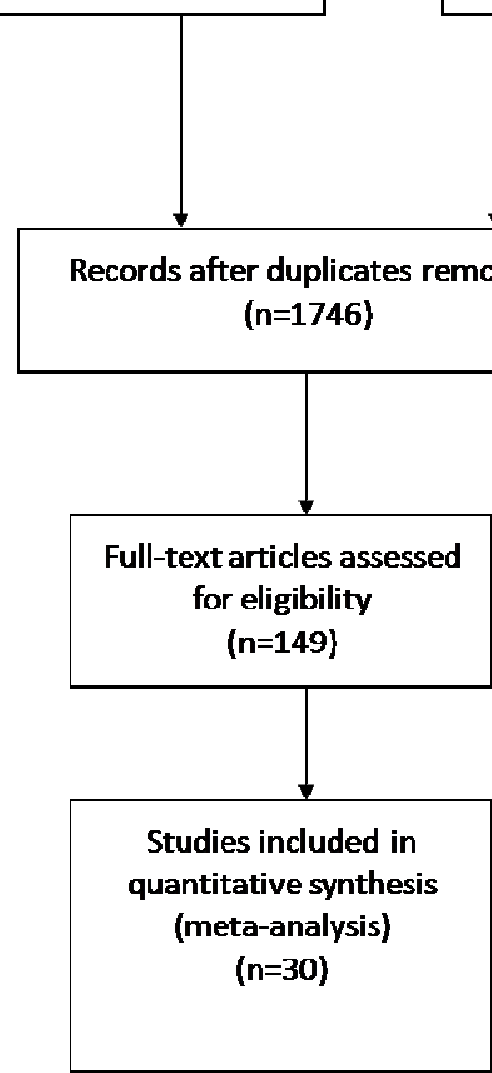

Additional records identified through other sources

$(n=12)$

Full-text articles excluded ( $n=119$ )

Non-GNG tasks ( $n=59)$

Not reporting the ISI ( $n=11$ ) or using a highly variable ISI $(\mathbf{n}=\mathbf{2 0})$

Self-paced tasks and tasks using extra stimuli such as feedback/cue $(n=24)$

Not reporting summary statistics or between group comparisons to calculate the ES ( $n=5)$ 
Metin et al.

Figure 2. Forest plots of effect sizes for mean reaction time at fast (left) and slow event rate (right) conditions of the within-subject studies.

Study name

\begin{tabular}{l|} 
van der Meere 2009 (36) \\
Borger and van der Meere 2000 (18) \\
Raymaekers 2007 (31) \\
Epstein 2011 (20) \\
Uebel 2010 (35) \\
Hervey 2006 (22) \\
Kunts 2009 (28) \\
Kooistra 2010 (27) \\
Wersema 2006 (adult) (43) \\
Rovet and Hepworth 2001 (32) \\
Wersema 2006 (42) \\
\end{tabular}

Std diff in means and $95 \% \mathrm{Cl}$

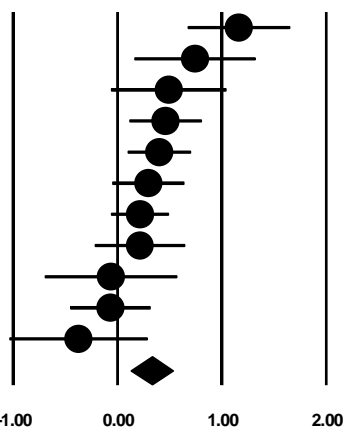

Study name

van der Meere 2009 (36)

Borger and van der Meere 2000 (18)

Wersema 2006 (adult) (43)

Hervey 2006 (22)

Raymaekers 2007 (31)

Rovet and Hepworth 2001 (32)

Epstein 2011 (20)

Kooistra 2010 (27)

Weræema 2006 (42)

Uebel 2010 (35)

Kunts 2009 (28)
Std diff in means and $95 \% \mathrm{Cl}$

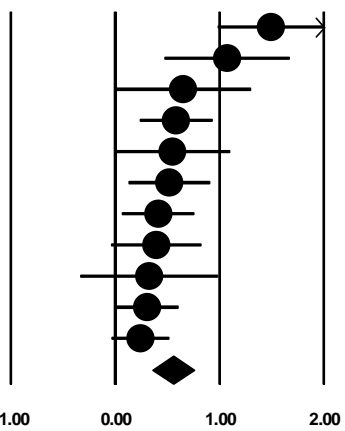


Metin et al.

Figure 3. Forest plots of effect sizes for commission errors at fast (left) and slow event rate (right) conditions of the within-subject studies.

Study name

\begin{tabular}{l|} 
van der Meere 2009 (36) \\
Wersema 2006 (42) \\
Raymaekers 2007 (31) \\
Epstein 2011 (20) \\
Kunts 2009 (28) \\
Uebel 2010 (35) \\
Wersema 2006 (adult) (43) \\
Rovet and Hepworth 2001 (32) \\
Hervey 2006 (22) \\
Kooistra 2010 (27) \\
Borger and van der Meere 2000 (18)
\end{tabular}

$-2.00$
Std diff in means and $95 \%$ a

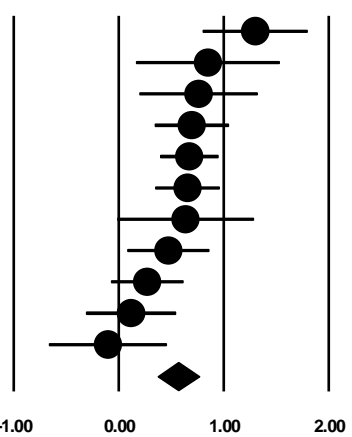

Study name

van der Meere 2009 (36) Epstein 2011 (20)

Uebel 2010 (35)

Kunts 2009 (28)

Raymaekers 2007 (31)

Bovet and Hepworth 2001 (32)

Wersema 2006 (adult) (43)

Kooistra 2010 (27)

Hervey 2006 (22)

Wersema 2006 (42)

Borger and van der Meere 2000 (18)

$-2.00$
Std diff in means and $95 \% \mathrm{C}$

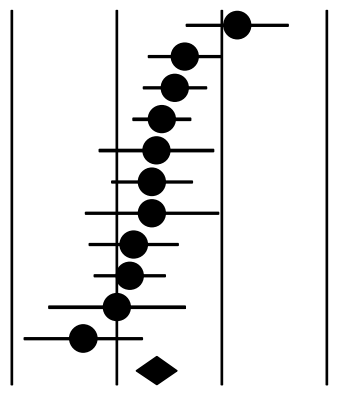


Metin et al.

Figure 4. Forest plots of effect sizes for reaction time variability at fast (left) and slow event rate (right) conditions of the within-subject studies.

Study name

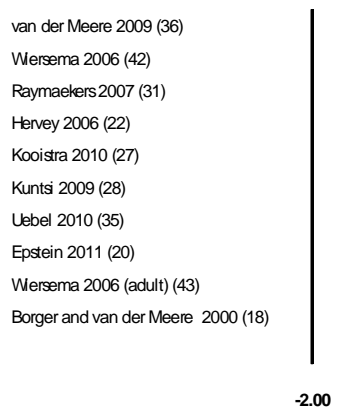

Std diff in means and $95 \% \mathrm{Cl}$

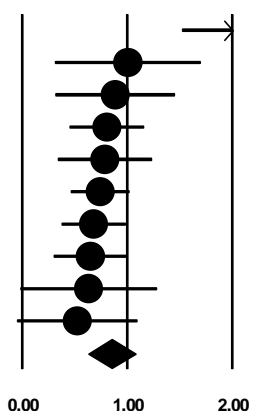

Study name

van der Meere 2009 (36) Borger and van der Meere 2000 (18) Wersema 2006 (42)

Hervey 2006 (22) Kunts 2009 (28) Wersema 2006 (adult) (43) Epstein 2011 (20) Uebel 2010 (35) Raymaekers 2007 (31) Kooistra 2010 (27)
Std diff in means and $95 \% \mathrm{C}$

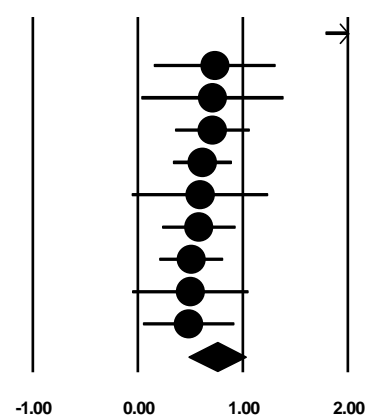


Metin et al.

Figure 5. Scatter plot for regression of ISI (inter-stimulus interval) on effect size for mean reaction time.

\section{Regression of ISI on Std diff in means}

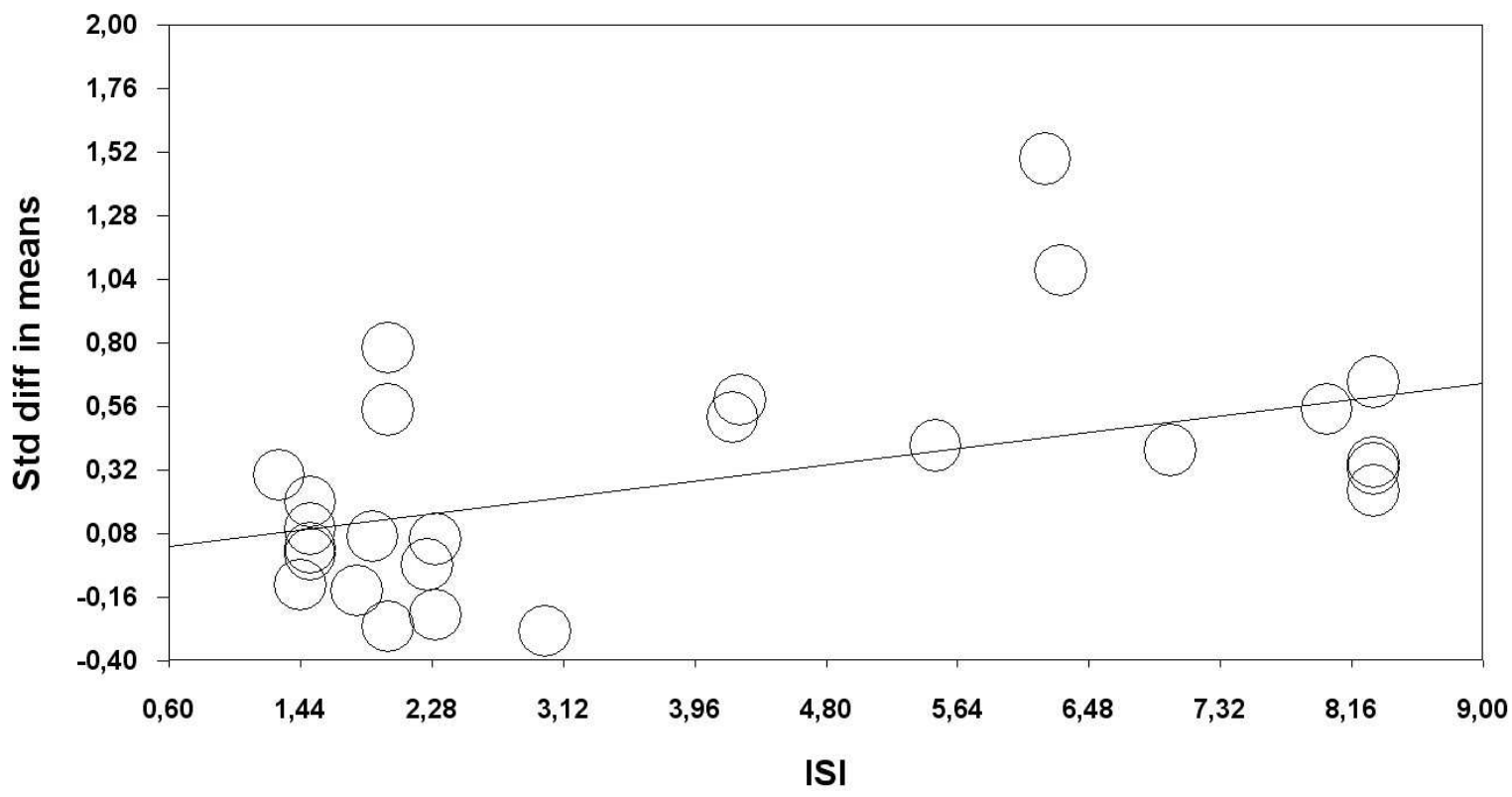




\section{A Meta-Analytic Study of Event Rate Effects on Go/No-Go Performance in Attention-Deficit/Hyperactivity Disorder}

\section{Supplemental Information}

\section{Details of the Data Extraction from the Studies and Calculation of Between-Study Effect Size}

The characteristics of the included studies are given in Table S1. The means and standard deviations for each outcome are given in Table S2.

As there were fewer studies with event rate (ER) manipulation and some of them did not report summary statistics to calculate the standardized mean difference, the results were obtained by personal communication with the authors for five studies $(18,20,27,31,36)^{1}$.

Five studies reported separate summary statistics for different ADHD subgroups with comorbidities (20, 27, 37, 38, 42). These were collapsed to form a single ADHD group data. One study reported results in two different age groups (17). We treated these results as independent studies. In five studies $(29,30,34,39,44)$ the reported variability parameter was the variability index (standard deviation divided by mean reaction time). As this index also reflected the intrasubject variability we included these results in the final analysis. However exclusion of these studies did not change any of the reported results.

For studies with manipulations in the Go/No-Go task such as using jittering interstimulus interval (34) or incentive conditions (19) the baseline conditions were used for effect size calculation.

\footnotetext{
${ }^{1}$ All reference numbers refer to those in the main text. See main text for complete reference details.
} 


\section{Analysis of Within-Subject Design Studies with Sensitivity Analysis}

As the correlations between different measurements are almost never reported in studies, we obtained the correlation coefficients for four studies via personal communication (Table S3). Based on these coefficients we ran a sensitivity analysis assuming a plausible range of correlation for the other studies. By this way we obtained highest and lowest possible range of synthetic effect sizes and $p$ values.

Two studies $(22,32)$ used more than two ERs. For the analysis of these studies, we used the comparison between fastest and the slowest ER.

\section{Meta-Regression}

To calculate the effect of age on effect sizes, studies conducted with older age groups were excluded to ensure homogeneity of the regressor $(17,21,41,43)$. The regression scatter plots for the effect of inter-stimulus interval on commission errors and variability are presented in Figures S1 and S2. 
Table S1. Characteristics of the included studies

\begin{tabular}{|c|c|c|c|c|c|c|c|c|c|}
\hline Study & $\begin{array}{c}\text { ISI } \\
(\mathbf{s e c})\end{array}$ & Age $^{\mathbf{a}}$ & $\begin{array}{l}\text { \%Male } \\
\text { ADHD }\end{array}$ & $\begin{array}{l}\text { \%Male } \\
\text { Control }\end{array}$ & No. Trial $^{\mathrm{c}}$ & $\% \mathrm{Go}^{\mathrm{d}}$ & Diagnosis $^{\mathbf{e}}$ & $\mathbf{I Q}^{\mathbf{f}}$ & $\mathbf{M S}^{\mathrm{g}}$ \\
\hline Berlin et al. 2000 (16) & 5.5 & 8.3 & 100 & 100 & 100 & 75 & C/HI(ODD+TS) & $>70$ & off \\
\hline Bistakou et al. 2008 (17) & 1.5 & 14.81 & 81 & 58 & 100 & 75 & $\mathrm{C}(\mathrm{ODD})$ & $>70$ & $>48$ \\
\hline Bistakou et al. 2008 (17) & 1.5 & $10.54^{\mathrm{h}}$ & 83 & 76 & 100 & 75 & $\mathrm{C}(\mathrm{ODD})$ & $>70$ & $>48$ \\
\hline $\begin{array}{l}\text { Borger and van der Meere } 2000 \\
\text { (18) }\end{array}$ & $\begin{array}{l}2.3 \\
6.3\end{array}$ & 10.1 & 100 & 100 & $\begin{array}{l}300 \\
100\end{array}$ & 80 & - & - & off \\
\hline Desman et al. 2008 (19) & 3 & 10.3 & 100 & 100 & 40 & 50 & $\mathrm{C}(\mathrm{CD})$ & $>80$ & $>24$ \\
\hline Epstein et al. 2011 (20) & $\begin{array}{l}1.5 \\
5.5\end{array}$ & 8.1 & 72 & 66 & $\begin{array}{l}120 \\
120\end{array}$ & 90 & $\mathrm{C} / \mathrm{A}(\mathrm{ODD}+\mathrm{CD})$ & $>80$ & off \\
\hline Groom et al. 2008 (21) & 2.25 & 15.69 & 93 & 42 & 304 & 80 & $\mathrm{C}$ & $>70$ & $>24$ \\
\hline Hervey et al. 2006 (22) & $\begin{array}{l}1.25 \\
4.25\end{array}$ & 10.7 & 77 & 77 & $\begin{array}{l}120 \\
120\end{array}$ & 90 & $\mathrm{C} / \mathrm{A} / \mathrm{HI}(\mathrm{CD}+\mathrm{ODD})$ & - & off \\
\hline Johnson et al. 2007 (23) & 1.4 & 11.4 & 84 & 72 & 225 & 88 & $\mathrm{C} / \mathrm{A} / \mathrm{HI}(\mathrm{CD}+\mathrm{ODD})$ & $>70$ & $>24$ \\
\hline Kerns et al. 2001 (24) & 1 & 9.4 & 76 & 76 & 150 & 50 & $\mathrm{C}$ & $>70$ & $>24$ \\
\hline Klein et al. 2006 (25) & 2.5 & 10.5 & 86 & 82 & 300 & 85 & $\mathrm{C} / \mathrm{A} / \mathrm{HI}(\mathrm{CD})$ & - & $>12$ \\
\hline Koschack et al. 2003 (26) & 2 & 11 & 91 & 60 & 50 & 50 & $\mathrm{C}(\mathrm{CD})$ & $>80$ & $>24$ \\
\hline Kooistra et al. 2009 (27) & $\begin{array}{c}1.5 \\
7\end{array}$ & 9.3 & 66 & 51 & $\begin{array}{c}210 \\
60\end{array}$ & 75 & $\mathrm{C} / \mathrm{A}$ & - & $>24$ \\
\hline Kuntsi et al. 2009 (28) & $\begin{array}{l}1.3 \\
8.3\end{array}$ & 8.8 & 91 & 48 & $\begin{array}{c}462 \\
72\end{array}$ & 80 & - & $>70$ & off \\
\hline McNally et al. 2010 (29) & 1.8 & 10.5 & 59 & 59 & 217 & 75 & $\mathrm{C} / \mathrm{A} / \mathrm{HI}(\mathrm{ODD})$ & $>85$ & $>24$ \\
\hline O’Brein et al. 2010 (30) & 1.8 & 10.2 & 53 & 53 & $\sim 267$ & 75 & $\mathrm{C} / \mathrm{A} / \mathrm{HI}(\mathrm{ODD})$ & $>80$ & $>24$ \\
\hline Raymaekers et al. 2007 (31) & $\begin{array}{l}2 \\
8\end{array}$ & 9.6 & 62 & 71 & $\begin{array}{c}300 \\
75\end{array}$ & 75 & $\mathrm{C} / \mathrm{IA}(\mathrm{ODD}+\mathrm{CD})$ & $>85$ & $>20$ \\
\hline
\end{tabular}




\begin{tabular}{|c|c|c|c|c|c|c|c|c|c|}
\hline Rovet and Hepworth 2001 (32) & $\begin{array}{l}1.2 \\
4.2\end{array}$ & 9.8 & 70 & 47 & $\begin{array}{l}40 \\
40\end{array}$ & 90 & - & $>75$ & $>24$ \\
\hline Rubia et al. 2007 (33) & 1.6 & 11.1 & 93 & 88 & 190 & 74 & $\mathrm{C}$ & $>75$ & $>24$ \\
\hline Ryan et al. 2010 (34) & 1.5 & 10.9 & 80 & 50 & 216 & 75 & $\mathrm{C} / \mathrm{A} / \mathrm{HI}(\mathrm{ODD})$ & $>70$ & $>24$ \\
\hline Uebel et al. 2010 (35) & $\begin{array}{l}1.3 \\
8.3\end{array}$ & 11.3 & 91 & 72 & $\begin{array}{c}462 \\
72\end{array}$ & 80 & $\mathrm{C}$ & - & $>48$ \\
\hline Van der Meere et al. 2009 (36) & $\begin{array}{l}2.15 \\
6.15\end{array}$ & 8 & 59 & 47 & $\begin{array}{l}300 \\
100\end{array}$ & 80 & $\mathrm{C} / \mathrm{HI}$ & - & $>36$ \\
\hline Van de Voorde et al. 2010 (37) & 2.3 & 10.6 & 83 & 58 & 600 & 80 & $\mathrm{C} / \mathrm{A} / \mathrm{HI}(\mathrm{ODD})$ & $>80$ & $>24$ \\
\hline Van de Voorde et al. 2010 (38) & 1.9 & 10.2 & 61 & 62 & 600 & 60 & C/A (ODD) & $>80$ & $>24$ \\
\hline Vaurio et al. 2009 (39) & 2.6 & 10.9 & 60 & 48 & 217 & 75 & $\mathrm{C} / \mathrm{A} / \mathrm{HI}(\mathrm{ODD})$ & $>80$ & $>24$ \\
\hline Wada et al. 2000 (40) & 2 & 9 & 100 & 100 & $\sim 169$ & 77.5 & $\mathrm{C} / \mathrm{A} / \mathrm{HI}$ & $>90$ & off \\
\hline Wiersema et al. 2009 (41) & 1.3 & 29.3 & 56 & 57 & $\sim 508$ & 75 & - & $>80$ & $>48$ \\
\hline Wiersema et al. 2006 (42) & $\begin{array}{l}2.3 \\
8.3\end{array}$ & 10.3 & 64 & 67 & $\begin{array}{c}287 \\
80\end{array}$ & 75 & $\mathrm{C}(\mathrm{CD}+\mathrm{ODD})$ & - & $>24$ \\
\hline Wiersema et al. 2006 (43) & $\begin{array}{l}2.3 \\
8.3\end{array}$ & 32.1 & 100 & 100 & $\begin{array}{c}287 \\
80\end{array}$ & 75 & - & $>80$ & $>48$ \\
\hline Wodka et al. 2007 (44) & 1.8 & 11.6 & 62 & 52 & 217 & 75 & $\mathrm{C} / \mathrm{A} / \mathrm{HI}(\mathrm{ODD})$ & $>85$ & $>18$ \\
\hline Yang et al. 2011 (45) & 1.5 & 8.4 & 90 & 89 & 200 & 80 & $\mathrm{CD}+\mathrm{ODD}$ & $>75$ & off \\
\hline $\begin{array}{l}{ }^{\mathrm{a}} \text { Mean age of the ADH } \\
{ }^{\mathrm{b}} \% \text { of males in the AD } \\
{ }^{\mathrm{c}} \text { Number of trials for e } \\
\text { the task duration and } \\
{ }^{\mathrm{d}} \% \text { of Go trials requirin } \\
{ }^{\mathrm{e}} \text { Diagnosis according } \\
\text { Oppositional Defiant } \\
{ }^{\mathrm{f}} \text { Lower cutoff for IQ. } \\
{ }^{\mathrm{g}} \text { Medicational status (h } \\
{ }^{\mathrm{h}} \text { The study included tw }\end{array}$ & $\begin{array}{l}\text { group. } \\
\text { group. } \\
\text { event } \\
\text { nt rate. } \\
\text { motor } \\
\text { DSM } \\
\text { order; } \\
\text { rs refra } \\
\text { ndenen }\end{array}$ & $\begin{array}{l}\text { cond } \\
\text { ponse } \\
\text { eria ( } \\
\text { Tour } \\
\text { d from } \\
\text { t subo }\end{array}$ & $\begin{array}{l}\text { Whe } \\
\text { mbir } \\
\text { indro } \\
\text { off, }\end{array}$ & $\begin{array}{l}\text { tal tr } \\
\text { Inat } \\
\text { dicati }\end{array}$ & $\begin{array}{l}\text { Der wa } \\
\text { HI, }\end{array}$ & $\begin{array}{l}\text { given } \\
\text { active }\end{array}$ & $\begin{array}{l}\text { approximate val } \\
\text { ulsive; CD, Co }\end{array}$ & As calc & $\begin{array}{l}\text { from } \\
\text { ODD, }\end{array}$ \\
\hline
\end{tabular}


Metin et al.

Table S2. Summary statistics ${ }^{\mathrm{a}}$ of the included studies

\begin{tabular}{|c|c|c|c|c|}
\hline Study & $n$ & MRT & EOC & SDRT \\
\hline $\begin{array}{l}\text { Berlin et al. } 2000 \\
\text { (16) }\end{array}$ & $\begin{array}{l}21 \mathrm{ADHD} \\
42 \mathrm{NC}\end{array}$ & & $\begin{array}{l}13.71(5.76) \\
11.04(5.22)\end{array}$ & \\
\hline $\begin{array}{l}\text { Bistakou et al. } 2008 \\
\text { (17) }\end{array}$ & $\begin{array}{l}54 \text { ADHD } \\
29 \mathrm{NC} \\
23 \mathrm{ADHD} \\
21 \mathrm{NC}\end{array}$ & $\begin{array}{l}378(108) \\
359(64) \\
324(123) \\
314(75)\end{array}$ & $\begin{array}{l}43.73(20) \\
28.2(19) \\
36.55(20) \\
33.54 \mid(17)\end{array}$ & $\begin{array}{l}197(169) \\
118(118) \\
150(174) \\
58(19)\end{array}$ \\
\hline $\begin{array}{l}\text { Borger and van der } \\
\text { Meere } 2000 \text { (fast) } \\
\text { (18) }\end{array}$ & $\begin{array}{l}27 \mathrm{ADHD} \\
22 \mathrm{NC}\end{array}$ & $\begin{array}{l}504(109) \\
428(91)\end{array}$ & $\begin{array}{l}37.81(18.95) \\
39.77(19.1)\end{array}$ & $\begin{array}{l}174.70(55.78) \\
149.41(36.77)\end{array}$ \\
\hline $\begin{array}{l}\text { Borger and van der } \\
\text { Meere } 2000 \text { (slow) } \\
\text { (18) }\end{array}$ & $\begin{array}{l}27 \mathrm{ADHD} \\
22 \mathrm{NC}\end{array}$ & $\begin{array}{l}652(118) \\
526(118)\end{array}$ & $\begin{array}{l}31.63(22.81) \\
38.95(23.06)\end{array}$ & $\begin{array}{l}243.52(124.15) \\
166.59(74.18)\end{array}$ \\
\hline $\begin{array}{l}\text { Desman et al. } 2008 \\
\text { (19) }\end{array}$ & $\begin{array}{l}19 \text { ADHD } \\
19 \text { NC }\end{array}$ & $\begin{array}{l}466.54(70.28) \\
495.37(122.63)\end{array}$ & $\begin{array}{l}3.11(2.21) \\
2.21(2.1)\end{array}$ & $\begin{array}{l}96.39(36.2) \\
97(44.75)\end{array}$ \\
\hline $\begin{array}{l}\text { Epstein et al. } 2011 \\
\text { (fast) (20) }\end{array}$ & $\begin{array}{l}104 \text { ADHD } \\
47 \text { NC }\end{array}$ & $\begin{array}{l}463(101) \\
416(105)\end{array}$ & $\begin{array}{l}10.9(7.1) \\
5.96(7.07)\end{array}$ & $\begin{array}{l}205.6(82.7) \\
151.8(82.4)\end{array}$ \\
\hline $\begin{array}{l}\text { Epstein et al. } 2011 \\
\text { (slow) (20) }\end{array}$ & $\begin{array}{l}104 \text { ADHD } \\
47 \mathrm{NC}\end{array}$ & $\begin{array}{l}801(357) \\
649(393)\end{array}$ & $\begin{array}{l}11.23(8.6) \\
5.6(8.9)\end{array}$ & $\begin{array}{l}452(264) \\
298(267)\end{array}$ \\
\hline $\begin{array}{l}\text { Groom et al. } 2008 \\
\text { (21) }\end{array}$ & $\begin{array}{l}27 \mathrm{ADHD} \\
36 \mathrm{NC}\end{array}$ & $\begin{array}{l}312.61(16.48) \\
313.3(20.64)\end{array}$ & & \\
\hline $\begin{array}{l}\text { Hervey et al. } 2006 \\
\text { (fast) (22) }\end{array}$ & $\begin{array}{l}65 \text { ADHD } \\
65 \mathrm{NC}\end{array}$ & $\begin{array}{l}381(58) \\
365(50)\end{array}$ & $\begin{array}{l}66.54(18.78) \\
60.9(22.63)\end{array}$ & $\begin{array}{l}155(36) \\
126(36)\end{array}$ \\
\hline $\begin{array}{l}\text { Hervey et al. } 2006 \\
\text { (slow) (22) }\end{array}$ & $\begin{array}{l}65 \mathrm{ADHD} \\
65 \mathrm{NC}\end{array}$ & $\begin{array}{l}530(123) \\
466(94)\end{array}$ & $\begin{array}{l}67.05(22.02) \\
64.23(23.12)\end{array}$ & $\begin{array}{l}340(196) \\
211(166)\end{array}$ \\
\hline $\begin{array}{l}\text { Johnson et al. } 2007 \\
\text { (23) }\end{array}$ & $\begin{array}{l}63 \mathrm{ADHD} \\
29 \mathrm{NC}\end{array}$ & $\begin{array}{l}456(89) \\
467(114)\end{array}$ & $\begin{array}{l}3.75(2.5) \\
2.3(1.6)\end{array}$ & \\
\hline Kerns et al. 2001 (24) & $\begin{array}{l}21 \mathrm{ADHD} \\
21 \mathrm{NC}\end{array}$ & & $\mathrm{t}^{\mathrm{b}}=1.52$ & \\
\hline Klein et al. 2006 (25) & $\begin{array}{l}57 \mathrm{ADHD} \\
53 \mathrm{HC}\end{array}$ & $\begin{array}{l}427.2(80.9) \\
389.4(53.9)\end{array}$ & $\begin{array}{l}19.5(7.7) \\
17.5(7.4)\end{array}$ & $\begin{array}{l}174(74.4) \\
115(43.2)\end{array}$ \\
\hline $\begin{array}{l}\text { Koschack et al. } 2003 \\
\text { (26) }\end{array}$ & $\begin{array}{l}35 \mathrm{ADHD} \\
35 \mathrm{NC}\end{array}$ & $\begin{array}{l}467(94) \\
492(91)\end{array}$ & $\begin{array}{l}6.2(5.2) \\
5.2(5.0)\end{array}$ & \\
\hline $\begin{array}{l}\text { Kooistra et al. } 2009 \\
\text { (fast) (27) }\end{array}$ & $\begin{array}{l}47 \mathrm{ADHD} \\
39 \mathrm{NC}\end{array}$ & $\begin{array}{l}446.13(51.7) \\
434.83(54.03)\end{array}$ & $\begin{array}{l}24.26(7.44) \\
23.32(8.49)\end{array}$ & $\begin{array}{l}129.91(19.35) \\
115.17(17.88)\end{array}$ \\
\hline $\begin{array}{l}\text { Kooistra et al. } 2009 \\
\text { (slow) (27) }\end{array}$ & $\begin{array}{l}47 \mathrm{ADHD} \\
39 \mathrm{NC}\end{array}$ & $\begin{array}{l}514.35(68.6) \\
686.1(74.98)\end{array}$ & $\begin{array}{l}5.65(2.71) \\
5.18(3.1)\end{array}$ & $\begin{array}{l}132.43(31.61) \\
118.74(23.65)\end{array}$ \\
\hline
\end{tabular}




\begin{tabular}{|c|c|c|c|c|}
\hline $\begin{array}{l}\text { Kuntsi et al. } 2009 \\
\text { (fast) (28) }\end{array}$ & $\begin{array}{l}58 \mathrm{ADHD} \\
1098 \mathrm{NC}\end{array}$ & $\begin{array}{l}434.44(71.95) \\
420.86(62.52)\end{array}$ & $\begin{array}{l}61.8(14.48) \\
50.86(16.36)\end{array}$ & $\begin{array}{l}202.33(69.04) \\
159.64(56.89)\end{array}$ \\
\hline \multirow{2}{*}{$\begin{array}{l}\text { Kuntsi et al. } 2009 \\
\text { (slow) (28) }\end{array}$} & 58 ADHD & 616.13 (179.49) & 64.36 (20.8) & 311.04 (232.44) \\
\hline & $1098 \mathrm{NC}$ & $584.38(129.02)$ & $54.52(23.12)$ & 219.26 (143.83) \\
\hline \multirow{2}{*}{$\begin{array}{l}\text { McNally et al. } 2010 \\
\text { (29) }\end{array}$} & 56 ADHD & & $39.4^{\mathrm{d}}$ & $0.39^{\mathrm{c}}$, \\
\hline & $45 \mathrm{NC}$ & & 33 & 0.32 \\
\hline \multirow{2}{*}{$\begin{array}{l}\text { O’Brein et al. } 2010 \\
\text { (30) }\end{array}$} & 56 ADHD & & 43(19) & $0.37(0.17)^{\mathrm{c}}$ \\
\hline & $90 \mathrm{NC}$ & & 35 (19) & $0.31(0.15)$ \\
\hline \multirow{2}{*}{$\begin{array}{l}\text { Raymaekers et al. } \\
2007 \text { (fast) (31) }\end{array}$} & 24 ADHD & $565.18(106.12)$ & $15.66(9.3)$ & 198.78 (53.72) \\
\hline & $28 \mathrm{NC}$ & 518.89 (82.87) & $9.17(7.8)$ & $144.81(48.1)$ \\
\hline \multirow{2}{*}{$\begin{array}{l}\text { Raymaekers et al. } \\
2007 \text { (slow) (31) }\end{array}$} & $24 \mathrm{ADHD}$ & 755.76 (211.49) & $2.95(2.44)$ & $262.79(292.54)$ \\
\hline & $28 \mathrm{NC}$ & 665.72 (108.16) & $2.0(2.58)$ & $158.24(89.25)$ \\
\hline \multirow{2}{*}{$\begin{array}{l}\text { Rovet and Hepworth } \\
2001 \text { (fast) (32) }\end{array}$} & 41 ADHD & 358.0 (81.3) & $61.3(24.7)$ & \\
\hline & $68 \mathrm{NC}$ & $363(67.1)$ & $49.5(25)$ & \\
\hline \multirow{2}{*}{$\begin{array}{l}\text { Rovet and Hepworth } \\
2001 \text { (slow) (32) }\end{array}$} & $41 \mathrm{ADHD}$ & 514.7 (131.3) & $67.0(21.2)$ & \\
\hline & $68 \mathrm{NC}$ & $457.3(96.2)$ & $58.2(28.9)$ & \\
\hline \multirow[t]{2}{*}{ Rubia et al. 2007 (33) } & $32 \mathrm{ADHD}$ & & $28(14)$ & \\
\hline & $34 \mathrm{NC}$ & & $19(15)$ & \\
\hline \multirow[t]{2}{*}{ Ryan et al. 2010 (34) } & 25 ADHD & 464.15 (177.52) & $29(22)$ & $0.35(0.13)^{\mathrm{c}}$ \\
\hline & $14 \mathrm{NC}$ & 463.98 (132.9) & 24 (19) & $0.23(0.07)$ \\
\hline \multirow{2}{*}{$\begin{array}{l}\text { Uebel et al. } 2010 \\
\text { (fast) (35) }\end{array}$} & 205 ADHD & 430 (114.48) & $50.3(24.72)$ & $183(114.54)$ \\
\hline & $53 \mathrm{NC}$ & 387 (72.8) & $34.8(18.92)$ & $110(72.8)$ \\
\hline \multirow{2}{*}{$\begin{array}{l}\text { Uebel et al. } 2010 \\
\text { (slow) (35) }\end{array}$} & 205 ADHD & $651(286.35)$ & $49.6(34.61)$ & 292 (272.03) \\
\hline & $53 \mathrm{NC}$ & 569 (182) & $31.3(26.21)$ & $162(174.72)$ \\
\hline \multirow{2}{*}{$\begin{array}{l}\text { Van der Meere et al. } \\
2009 \text { (fast) (36) }\end{array}$} & 26 ADHD & $614.62(98.48)$ & $60.05(18.6)$ & 331.46 (80.01) \\
\hline & $60 \mathrm{NC}$ & 511.75 (83.92) & 38.05 (16.15) & $188.22(63.78)$ \\
\hline \multirow{2}{*}{$\begin{array}{l}\text { Van der Meere et al. } \\
2009 \text { (slow) (36) }\end{array}$} & 26 ADHD & 965.85 (332.5) & $58.45(22.07)$ & 819.88 (433.68) \\
\hline & $60 \mathrm{NC}$ & 644.62 (137.64) & $32.25(22.15)$ & $224.08(102.16)$ \\
\hline \multirow{2}{*}{$\begin{array}{l}\text { Van de Voorde et al. } \\
2010 \text { (37) }\end{array}$} & 40 ADHD & 497.32 (91.99) & 38.77 (18.2) & $174.12(50.5)$ \\
\hline & $19 \mathrm{NC}$ & 518.7 (98.9) & $17.9(10.9)$ & $151.3(51.2)$ \\
\hline \multirow{2}{*}{$\begin{array}{l}\text { Van de Voorde et al. } \\
2010 \text { (38) }\end{array}$} & 31 ADHD & $517.6(81.2)$ & 35.13 (12.76) & $179(33.2)$ \\
\hline & $16 \mathrm{NC}$ & $512.2(72.2)$ & $23.4(9.1)$ & $156.8(33.7)$ \\
\hline \multirow{2}{*}{$\begin{array}{l}\text { Vaurio et al. } 2009 \\
\text { (39) }\end{array}$} & 57 ADHD & 401.55 (85.02) & $38(20)$ & $0.35(0.13)^{\mathrm{C}}$ \\
\hline & $83 \mathrm{NC}$ & 395.62 (109.47) & 29 (19) & $0.28(0.12)^{\mathrm{C}}$ \\
\hline \multirow[t]{2}{*}{ Wada et al. 2000 (40) } & $17 \mathrm{ADHD}$ & 523.76 (181.91) & 33.41 (19.11) & 221.41 (103.29) \\
\hline & $19 \mathrm{NC}$ & 416.47 (79.92) & $16.56(9.85)$ & $109.31(49.11)$ \\
\hline
\end{tabular}


Metin et al.

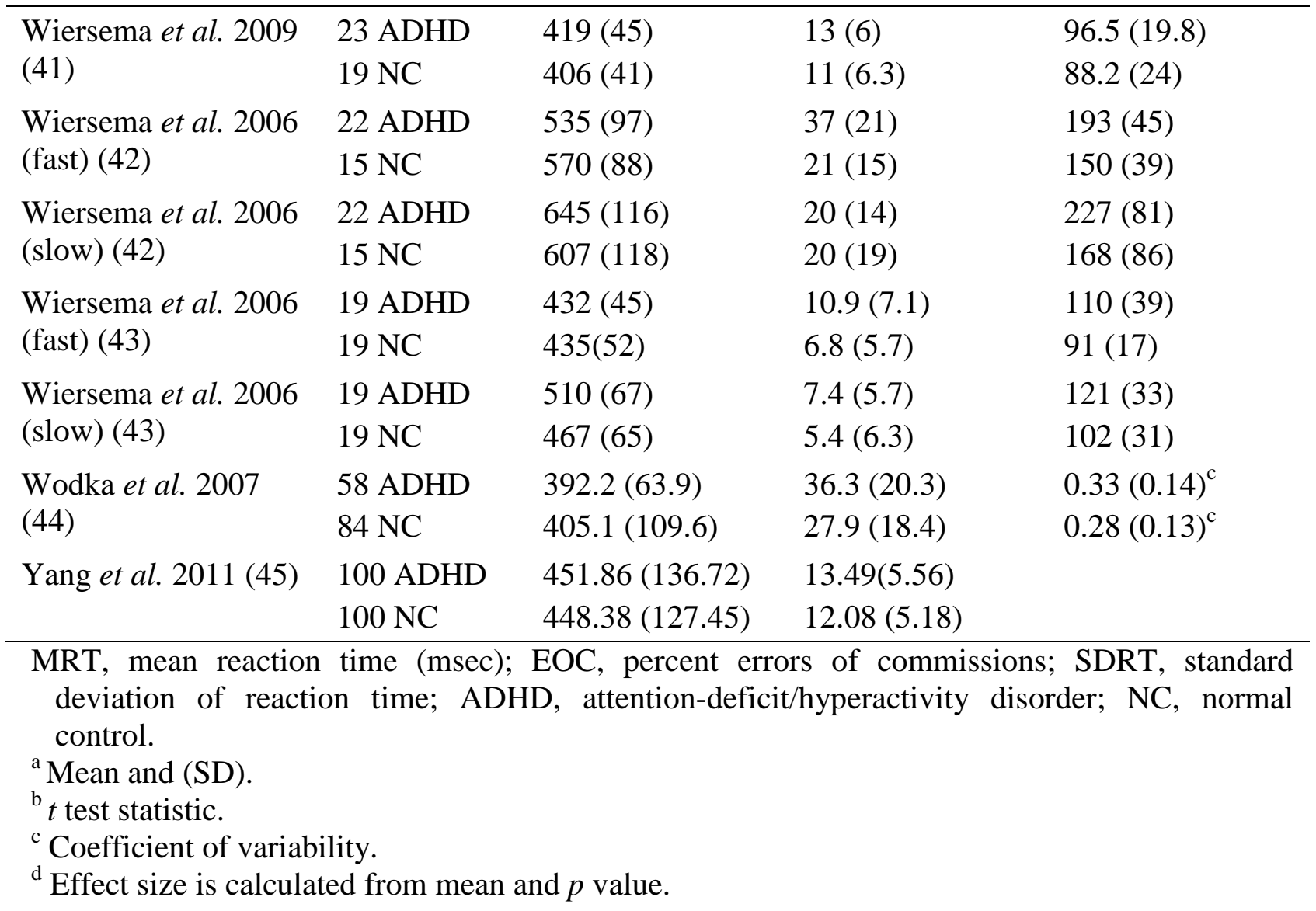


Metin et al.

Table S3. Correlations between event rates.

\begin{tabular}{lccc}
\hline Study & MRT & EOC & SDRT \\
\hline Borger and van der Meere 2000 (18) & 0.76 & 0.59 & 0.77 \\
Kooistra et al. 2010 (27) & 0.81 & 0.48 & 0.64 \\
Raymaekers et al. 2007 (31) & 0.70 & 0.6 & 0.65 \\
van der Meere et al. 2009 (36) & 0.69 & 0.72 & 0.75 \\
\hline MRT, mean reaction time (msec); EOC, percent errors of commissions; SDRT, \\
standard deviation of reaction time.
\end{tabular}


Metin et al.

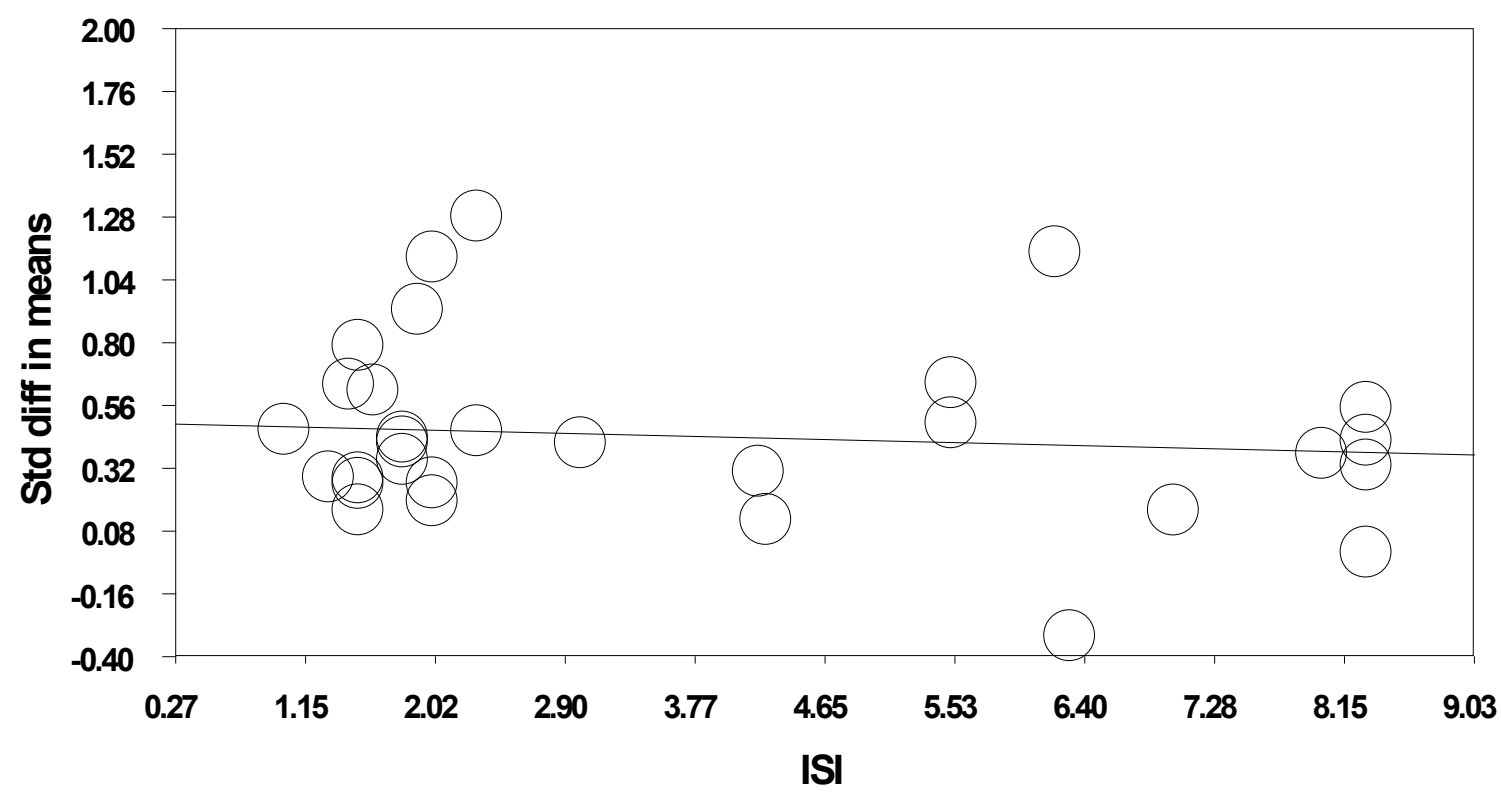

Figure S1. Scatter plot for regression of ISI (inter-stimulus interval) on effect size for commission errors. 
Metin et al.

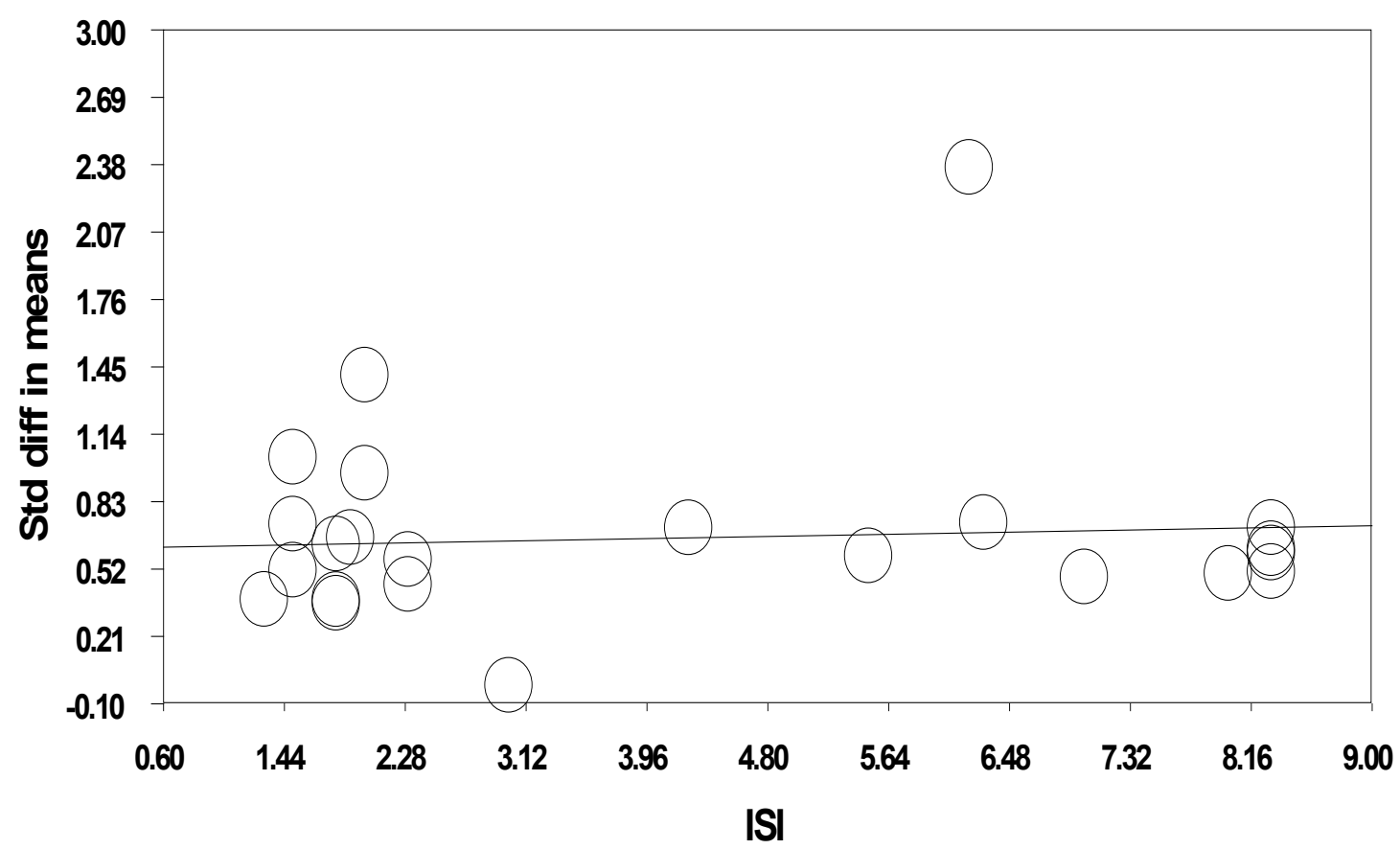

Figure S2. Scatter plot for regression of ISI (inter-stimulus interval) on effect size for reaction time variability. 